PROBLEMS

OF MANAGEMENT

IN THE $21^{\text {st }}$ CENTURY

Volume 5, 2012

\section{HUMAN RESOURCE INFORMATION SYSTEM AS A STRATEGIC TOOL IN HUMAN RESOURCE MANAGEMENT}

\author{
Ebenezer Ankrah, Evans Sokro \\ Central University College, Ghana \\ E-mail: ebankrah@yahoo.com, evanssokro@gmail.com
}

\begin{abstract}
The purpose of this research is to identify specifically, how the use of Human Resource Information Systems (HRIS) contributes to the effectiveness of strategic human resources management and to examine the strategic importance of using HRIS at the workplace. Relevant review of various HRIS literature were undertaken which culminated into the development of a conceptual model and the formulation of hypotheses to test the proposal that there is relationship between independent variables- HRIS- and the dependent variables- Cost and Time Savings (CTS), Decision Making Contribution (DMC), Quality Information Effects (QIE) and Employment Development Commitment (EDC). The research uses data generated from 34 respondents from insurance companies in Ghana: SSNIT, ELAC, Vanguard, and Donewell. Data was analyzed using SPSS software. It has been found that HRIS adoption and use have a strong and positive effect on CTS and DMC. Essentially, organizations that divert concerted efforts towards HRIS adoption and use have a high likelihood of cutting down cost and saving time, and also ensure better contributions to strategic decision making. Further findings suggest that insurance organizations map up a strategic plan before implementation goes underway. Financial and resource appraisal in relation to the ability to start and sustain HRIS use are critical. HRIS enables HR professionals and supervisors to manage complex information entities and to plan HR efficiently also, organisations that intend using HRIS should thoroughly educate its employees- not only HR staff-so that internal awareness can facilitate the acceptance of the system.
\end{abstract}

Key words: human resource information system, strategic human resource management, strategic decision making.

\title{
Introduction
}

The use of Human Resource Information Systems (HRIS) has been advocated as an opportunity for human resource (HR) professionals to become strategic partners with top management (Lengnick-Hall and Moritz, 2003). The idea has been that HRIS would allow for the HR function to become more efficient and to provide better information for decisionmaking. The question remains whether HRIS has fulfilled its promise. In its most basic form HRIS is a system used to acquire, store, manipulate, analyze, retrieve and distribute pertinent information about an organization's human resources. It is often regarded as a service provided to an organization in the form of information (Tannenbaum, 1990). However, the promise is that, as the use of these systems become more widespread, higher level forms of HRIS will evolve.

Lengnick-Hall and Moritz (2003) have postulated that HRIS will be implemented at three different levels: the publishing of information; the automation of transactions; and, finally, a change in the way human resource management is conducted in the organization by transforming HR into a strategic partner with the line business. In their view, the evolution 
of HR as promoted by HRIS evolves from information to automation and from automation to transformation. They note that while HRIS has been widely deployed, a transformation of human resource management has occurred in relatively few organizations. The evolution that Lengnick-Hall and Moritz propose, along with others (e.g., Walker, 2001), revolves around the perspective that HRIS will create informational efficiencies and cost savings such that HR departments can turn their attention to providing better analysis of current data and creative uses of the HRIS to provide better and more accurate data upon which to base strategic decisions. Overman (1992), concluded that the potential advantages of HRIS are faster information processing, greater information accuracy, improved planning and program development, and enhanced employee communications.

\section{Problem of Research}

Organizations become more complex and as the amount of information they need increases the need for automated information systems increase dramatically. The organization determines what kind of information it will need by deciding what kind of decision it will be making based on the HRIS information and which will be the decision maker. Because these needs are likely to change over time, it is also necessary to build a certain amount of flexibility. However, human resources information systems ( HRIS) is more than a simple aggregation mechanism for inventory control and accounting ; it is the foundation for a set of management tools enabling managers to establish objectives for the use of their organization's human resources and to measure the extent to which those objectives have been achieved. As managers come to recognize both the essentiality and feasibility of sophisticated management information systems for monitoring human resources, more and more computerized personnel management information systems such as HRIS will be installed (Orlando and Johnson, 2004).

A significant problem with deciding whether HRIS benefits the organization is that of measuring the effect of HR and more particularly HRIS on the bottom line. There are few clear cut ways to measure the value of HRIS. While there are measurements for administrative HRIS such as cost reductions in HR departments, it is difficult to measure precisely the return on investment and specific improvements in productivity within the HR, there is a link between human resource information systems (HRIS) and strategic human resources. To gain vital information to be able to compete in a competitive environment, the study seeks to have an in depth analysis of the issue at hand. These and other related issues provided the foundation for this research to be carried out in order to investigate the strategic role of HRIS in human resource management. The main objective of the study is to identify specifically, how the use of Human Resource Information Systems (HRIS) contributes to the effectiveness of strategic human resources management and to examine the strategic importance of using HRIS at the workplace.

\section{Research Focus}

\section{Development and Role of HRIS}

Recent developments in technology have made it possible to create a real-time information-based, self-service, and interactive work environment. Personnel Information Systems have evolved from the automated employee recordkeeping from the 1960s into more complex reporting and decision systems of late. Today, managers and employees are assuming activities once considered the domain of human resource professionals and administrative personnel. HRIS meet the needs of a number of organizational stakeholders. Typically, the people in the firm who interact with the HRIS are segmented into three groups: HR professionals, 
PROBLEMS

OF MANAGEMENT

IN THE $21^{\text {st }}$ CENTURY

Volume 5, 2012

managers in functional areas (production, marketing, engineering etc.), and employees. HR professionals rely on the HRIS in fulfilling job functions (regulatory reporting and compliance, compensation analysis, payroll, pension, and profit sharing administration, skill inventory, benefits administration etc.). Thus, for the HR professional there is an increasing reliance on the HRIS to fulfil even the most elementary job tasks. As human capital plays a larger role in competitive advantage, functional managers expect the HRIS to provide functionality to meet the unit's goals and objectives. Moreover, managers rely on the HRIS's capabilities to provide superior data collection and analysis, especially for performance appraisal and performance management.

Additionally, it also includes skill testing, assessment and development, résumé processing, recruitment and retention, team and project management, and management development. Finally, the individual employees become end users of many HRIS applications. The increased complexity of employee benefit options and the corresponding need to monitor and modify category selections more frequently has increased the awareness of HRIS functionality among employees. Web-based access and self-service options have simplified the modification process and enhanced the usability of many benefit options and administration alternative for most employees.

Apparently, data entry in the past had been one way, but today, scanning technology permits scanning and storage of actual image off an original document, including signatures and handwritten notes. The maintenance function updates and adds new data to the database after data have been entered into the information system. Moreover, the most visible function of an HRIS is the output generated. According to Kovach et al., (1999), to generate valuable output for computer users, the HRIS have to process that output, make the necessary calculations, and then format the presentation in a way that could be understood. However, the note of caution is that, while it is easy to think of HR information systems in terms of the hardware and software packages used to implement them and to measure them by the number of workstations, applications or users who log onto the system, the most important elements of HRIS are not the computers, rather, the information. The bottom line of any comprehensive HRIS have to be the information validity, reliability and utility first and the automation of the process second.

\section{Impact of HRIS on Human Resource Management}

The human resource strategy has a significant role in supporting the implementation of the strategy of an organization. Strategic human resource management seeks an answer to the question: How does an organization plan, organize, control and develop human resources to carry out its strategy and to renew its competitive position?

HRIS have tremendous effects on the system of Human Resource Management (HRM). In this direction, a lot of the literature covering the link between human resource management and firm performance is based on the universalistic or "best practices" perspective that "implies a direct relationship between particular approaches to human resources and performance". Many researchers have empirically supported universalistic predictions especially in context where HRIS is concerned. First there are those who focus on a single or several HRM practices and examine their effect on various performance measures. There are also similar studies examining the effect of bundles, or systems, of HRM practices on performance. This stream of research implies that firms should create a high degree of internal consistency among their HR activities. A detailed diagram of an integrated HRIS oriented to strategic needs of organizations is provided by Smith in 1980. Categories in the input transformation and output sections could be used as criteria for an HRIS. Various criteria mainly related to technical and database management systems, but informative to HRIS development, are scattered throughout the article:

a) Data files should be integrated for easy cross-referencing among various departments and redundancy of data minimized. 
b) Crucial data should be available on request (i.e. online). Critical information includes: the location of key employees, essential skills data, and promotion and performance information.

c) Appropriate variables for measurement are: employee turnover; absenteeism; type of grievances; frequency of accidents; requests for transfers; trends in personnel costs.

d) Quantifiable measures can include: attitudinal data correlated with demographics, performance and costs.

e) Standard and unplanned reports should be available on a timely basis, including immediate feedback on employee turnover, financial ratios and recruiting results. More sophisticated reporting for career profiles, job applicants' review, etc., is desirable.

f) Advanced features, such as matching current personnel to future needs of an organization, succession planning, organizational change models and identification of prospective future managers and facilitation of their growth and development, which would enhance their performance.

\section{Costs and Benefits of HRIS}

An HRIS system represents a large investment decision for companies of all sizes. Therefore, a convincing case to persuade decision makers about the HRIS benefits is necessary. The common benefits of HRIS frequently cited in studies included, improved accuracy, the provision of timely and quick access to information, and the saving of costs (Lederer, 1984; Wille and Hammond, 1981). Lederer (1984) discussed why the accuracy and timeliness of HRIS is very important in terms of operating, controlling, and planning activities in HR. In addition, Kovach et al., (2002) listed several administrative and strategic advantages to using HRIS. Similarly, Beckers and Bsat (2002) pointed out at least five reasons why companies should use HRIS. These are:
a) Increase competitiveness by improving HR practices.
b) Produce a greater number and variety of HR operations.
c) Shift the focus of HR from the processing of transactions to strategic HRM.
d) Make employees part of HRIS, and
e) Reengineer the entire HR function.

Ball (2001) reviewed the issues surrounding the use of HRIS by personnel and human resources departments in smaller organizations. The study enquired as to the nature of information stored electronically in three core areas: personnel, training and recruitment. Additionally, the paper evaluated system usage in terms of previous research, its sophistication, and other debates, which apply to larger firms. The study employed empirical data, which profiled system usage by $115 \mathrm{UK}$ companies in the service sector in terms of information stored on personnel, training and recruitment and information processing features used. Ball (2001) revealed that the more people employed in an organization, the more likely the HR function was to hold information electronically both on the individual and the organization. Similarly, the more people organization employed, the more likely it was that information analysis with HRIS would occur. However, only half of the firms who employed less than 500 employees, and those who used only core HR modules, rather than additional training and recruitment modules used HRIS. Moreover, the more people employed by the organization the less likely it was to purchase additional non-core HR modules. Consequently, organizations that had purchased HRIS were more likely to buy additional modules. In general, HRIS had wider usage administratively, although those who used HRIS in training and recruitment were beginning to move away from this. Finally, time and attendance were the most frequent integrated additional modules (Ibid).

The findings from Ball (2001) reveal that organizational size is a clear determinant of, 
PROBLEMS

OF MANAGEMENT IN THE $21^{\text {st }}$ CENTURY Volume 5, 2012

first, whether an organization has an HRIS at all and, second, whether it adopts certain modules over others, and third how information is used and analyzed. Similarly, the type of software chosen by new HRIS users was typically a low-cost option. In-house database development was an equally popular option for smaller organizations adopting HRIS for the first time. This was in line with Thaler-Carter's (1998) observations that smaller organization would go for low cost and low risk HRIS purchases, typically cheaper, supplementary software that were flexible or in-house HRIS development.

In a more recent study, Hussain et al., (2006) investigated into the use and impact of human resource information systems on human resource management professionals. The aim was to assess and compare the specific areas of use and to introduce a taxonomy that provides a framework for academicians. They also sought to determine whether HRIS usage was strategic, a perceived value-added for the organization, and its impact on professional standing for HR professionals. The results showed that, on average, few differences existed between SME and large company HRIS' usage. Further, the authors observed that the professional standing has been enhanced by the specific HRIS usage for strategic collaborating, but cautioned that it was not as pronounced as that experienced by those other professions. Invariably, the researchers noted that for senior HR professionals, strategic use of HRIS was increasingly the norm, irrespective of company size. In addition, they observed that strategic use of HRIS enhanced the perceived standing of HR professionals within organizations; senior non-HR executives however did not share this view.

\section{Theoretical Framework}

HRIS literature (e.g. Beadles et al., 2005; Kovach et al., 2002; Ball, 2000; Overman, $1992)$ is replete with the strategic role HRIS plays to enhance management decisions. It has been established that the potential advantages of HRIS are faster information processing, greater information accuracy, improved planning and program development, and enhanced employee communications. This study, following from previous studies, will focus on four key areas in which HRIS is noted to influence HRM and organizational performance. They are:

- Savings in cost and time.

- Contributions to strategic decision making.

- Quality of information effects.

- Commitment to employee development.

Therefore, the study worked with the research model below:

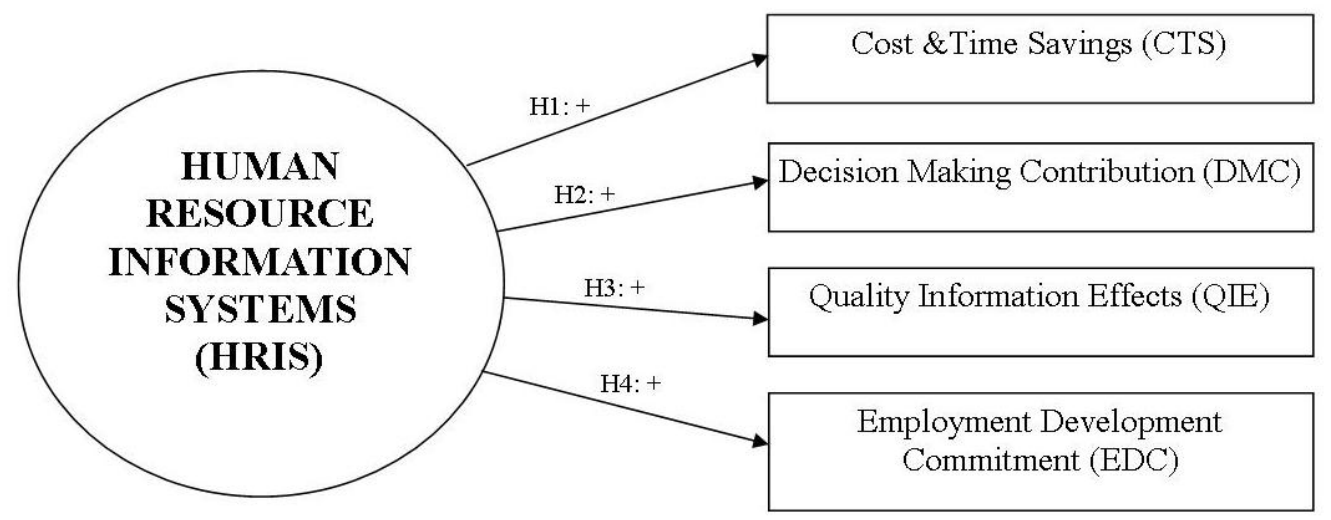

Figure 1: Research Model: Conceptualising the Strategic Role of HRIS. 


\section{Methodology of Research}

General Background of Research

In this study, a conclusive research design was used. This is because by reviewing literature, needed information and constructs have been clearly specified. Additionally, this study intends to test four HRIS hypotheses (Cost and Time Savings, Decision Making Contributions, Quality Information Effects, Employee Development Commitments) and understand the specific relationships HRIS has with HRM. For this study, the target population was HR professionals, HR directors, HR managers in Ghana. Particularly, these respondents were drawn from three industries: Telecommunications, Banking, and Foods and Beverages.

\section{Sample of Research}

A Proportionate Sample size of eighty (80) was used for this study representing eighty percentage of the total population. However, due to time and financial constraints, only 63 responses were obtained. Some responded questionnaires were found to be incomplete and others wrongly filled; thus only 57 were used for further analysis.

\section{Research Instrument, Procedures and Data Analysis}

The survey was developed using questionnaires as the main instrument for data collection. Likert-type items on a five point scale and open-ended questions were employed on the survey to measure the perceptions of the HR directors in regard to the impact of the HRIS on HR processes, the time spent on various HR activities, the expense of HR activities, levels and use of information within the organization, the role of the HR department, and strategic decision making. Both qualitative and quantity data analysis techniques were used in analysing the data.

Table 1. Reliability Statistics.

\begin{tabular}{|l|c|c|}
\hline Scale & Cronbach's Alpha & Number of Items \\
\hline Cost \& Times Savings (CTS) & 0.598 & 3 \\
\hline Decision Making Contribution (DMC) & 0.826 & 3 \\
\hline Quality Information Effects (QIE) & 0.734 & 3 \\
\hline Employment Development Commitment (EDC) & 0.855 & 3 \\
\hline HRIS Use & 0.678 & 3 \\
\hline
\end{tabular}

For purposes of this study, reliability of data is tested on the scales used to measure the four independent and one dependent variable using the Cronbach's alpha coefficients. Ideally a value above 0.7 confirms the internal consistency of the scales. The results, as shown in Table 1 Reliability Statistics above, indicate that three of the scales used to measure Decision Making Contribution (DMC), Quality Information Effects (QIE) and Employment Development Commitment (EDC) have internal consistency with Cronbach values of $0.826,0.734$, and 0.855 respectively. Whiles HRIS was near to record undisputed internal consistency in its scales by the 0.678 value, scales for Cost \& Time Savings lacked consistency. 
PROBLEMS OF MANAGEMENT IN THE $21^{\text {st }}$ CENTURY Volume 5, 2012

\section{Results of Research}

\section{Evaluating the Model}

The importance of the impact of HRIS on the four dependent variables can be evaluated using the effect size statistic (see Table 2): Partial Eta Squared (Pallant, 2003). Partial Eta Squared represents the proportion of the variance in the dependent variables (CTS, DCM, QIE, and EDC) that can be explained by the independent variable (HRIS). Eta squared represents the proportion of variance of the dependent variable that is explained by the independent variable. Values for eta squared can range from 0 to 1.

To interpret the strength of eta squared values the following guidelines can be used (from Cohen, 1988):

- $0.01=$ small effect;

- $0.06=$ moderate effect; and

- $0.14=$ large effect.

Based on these criteria, the following findings can be drawn about the impact of HRIS use on our various independent variables.

Table 2. Tests of Between-Subjects Effects.

\begin{tabular}{|c|c|c|c|c|c|c|}
\hline Source & $\begin{array}{c}\text { Dependent } \\
\text { Variable }\end{array}$ & $\begin{array}{l}\text { Type III Sum } \\
\text { of Squares }\end{array}$ & df & $\mathbf{F}$ & Sig. & $\begin{array}{c}\text { Partial Eta } \\
\text { Squared }\end{array}$ \\
\hline $\begin{array}{c}\text { Corrected } \\
\text { Model }\end{array}$ & $\begin{array}{c}\text { CTStot } \\
\text { DMCtot } \\
\text { QIEtot } \\
\text { EDCtot }\end{array}$ & $\begin{array}{c}72.398^{\mathrm{a}} \\
126.775^{\mathrm{b}} \\
58.168^{\mathrm{c}} \\
165.050^{\mathrm{d}} \\
\end{array}$ & $\begin{array}{l}7 \\
7 \\
7 \\
7 \\
\end{array}$ & $\begin{array}{l}7.654 \\
7.643 \\
2.581 \\
4.763 \\
\end{array}$ & $\begin{array}{l}0.000 \\
0.000 \\
0.037 \\
0.001 \\
\end{array}$ & $\begin{array}{l}0.673 \\
0.673 \\
0.410 \\
0.562 \\
\end{array}$ \\
\hline Intercept & $\begin{array}{l}\text { CTStot } \\
\text { DMCtot } \\
\text { QlEtot } \\
\text { EDCtot }\end{array}$ & $\begin{array}{l}786.742 \\
921.463 \\
770.100 \\
993.184\end{array}$ & $\begin{array}{l}1 \\
1 \\
1 \\
1\end{array}$ & $\begin{array}{l}582.259 \\
388.884 \\
239.178 \\
200.621\end{array}$ & $\begin{array}{l}0.000 \\
0.000 \\
0.000 \\
0.000\end{array}$ & $\begin{array}{l}0.957 \\
0.937 \\
0.902 \\
0.885\end{array}$ \\
\hline HRIStot & $\begin{array}{l}\text { CTStot } \\
\text { DMCtot } \\
\text { QlEtot } \\
\text { EDCtot }\end{array}$ & $\begin{array}{c}72.398 \\
126.775 \\
58.168 \\
165.050\end{array}$ & $\begin{array}{l}7 \\
7 \\
7 \\
7\end{array}$ & $\begin{array}{l}7.654 \\
7.643 \\
2.581 \\
4.763\end{array}$ & $\begin{array}{l}0.000 \\
0.000 \\
0.037 \\
0.001\end{array}$ & $\begin{array}{l}0.673 \\
0.673 \\
0.410 \\
0.562\end{array}$ \\
\hline Error & $\begin{array}{c}\text { CTStot } \\
\text { DMCtot } \\
\text { QlEtot } \\
\text { EDCtot }\end{array}$ & \begin{tabular}{|c|}
35.131 \\
61.607 \\
83.714 \\
128.714 \\
\end{tabular} & $\begin{array}{l}26 \\
26 \\
26 \\
26\end{array}$ & & & \\
\hline Total & $\begin{array}{l}\text { CTStot } \\
\text { DMCtot } \\
\text { QlEtot } \\
\text { EDCtot }\end{array}$ & $\begin{array}{c}998.000 \\
1239.000 \\
1012.000 \\
1378.000\end{array}$ & $\begin{array}{l}34 \\
34 \\
34 \\
34\end{array}$ & & & \\
\hline $\begin{array}{c}\text { Corrected } \\
\text { Total }\end{array}$ & $\begin{array}{l}\text { CTStot } \\
\text { DMCtot } \\
\text { QlEtot } \\
\text { EDCtot }\end{array}$ & $\begin{array}{l}107.529 \\
188.382 \\
141.882 \\
293.765\end{array}$ & $\begin{array}{l}33 \\
33 \\
33 \\
33\end{array}$ & & & \\
\hline \multicolumn{7}{|c|}{ a. R Squared $=0.673$ (Adjusted R Squared $=0.585)$} \\
\hline \multicolumn{7}{|c|}{ b. R Squared $=0.673$ (Adjusted R Squared $=0.585)$} \\
\hline \multicolumn{7}{|c|}{ c. R Squared $=0.410$ (Adjusted R Squared $=0.251)$} \\
\hline \multicolumn{7}{|c|}{ d. R Squared $=0.562$ (Adjusted R Squared $=0.444)$} \\
\hline
\end{tabular}


Hypothesis $1\left(H_{1}\right)$ : The greater the use of HRIS, the higher the operational savings in terms of 13

cost and time

This hypothesis is supported by the statistic Partial Eta Squared=0.673. Since this value is greater than Cohen's 0.14, it suggests that HRIS is positively correlated (i.e. has a massive impact) to cost and time savings. This, according to Pallant (2003) means, converted to percentages, HRIS uses accounts for 67 percent of the variance in cost and time savings in an organization. The results reflect findings from previous studies (e.g. Kovach and Cathcart, 1999) which suggest that a key advantage of HRIS is that processing costs is reduced. Even more strongly, Ngai and Watt (2006) found that the perceived benefit of a "quick response and access to information" had the highest mean score in their survey. Similarly, Teo et al. (2001) reported in their study that the advantage of a more timely management reporting as a result of HRIS adoption was the leading benefit.

Hypothesis $2\left(\mathrm{H}_{2}\right):$ The greater the use of HRIS, the better the contributions to strategic decision making

This hypothesis is also supported by the statistic Partial Eta Squared $=0.673$. Using Cohen's standard, it can be concluded that HRIS has a massive impact on decision making in an organization. Statistically, HRIS contributes not less than 67 percent of strategic input to decision making. Our findings here corroborate the assertions of Lengnick-Hall and Moritz (2003) who reported that the functions provided by HRIS allow a strategic type and amount of information to be provided to top management and the HR department which helps to make better decisions. Particularly, Beadles et al. (2005) found that one area where respondents believed that the system did aid in making decisions concerns promotions, with $60 \%$ responding that it provides useful information.

Hypothesis $3\left(H_{3}\right)$ : The greater the use of HRIS, the better the quality of information effects

Considering the Partial Eta Squared $=0.410$, this hypothesis has been statistically proven. Although the strength is a little lower than CTS and DMC, it passes Cohen's criteria, and thus it can be concluded that HRIS contributes 40 percent of quality information to firms. Beadles et al. (2005) also found a positive yet moderate relationship between HRIS and quality of information. The deduction here is that quality information can be seen as means to an end (i.e. better DMC) and not necessarily a distinct achievement in itself; thus separating them as distinct scales is likely to yield such a moderate effect.

Hypothesis $4\left(\mathrm{H}_{4}\right)$ : The greater the use of HRIS, the higher the commitment to employee development

Similarly this hypothesis is supported by the statistic Partial Eta Squared $=0.562$. Since this value is greater than Cohen's 0.14 , it suggests that HRIS is positively correlated to employee development commitments. Percentage-wise according to Pallant's (2003) elucidation, HRIS use accounts for more than half of the variance in employee development commitments. This may not be as strong as the impacts on CTS and DMC, but according to Ball (2001), who reported a relatively low impact of HRIS on employee development (e.g. skills matching and training), the reason is because using HRIS to perform such tasks can be more complex and analytical in nature and thus lower patronage. 
According to the data analysis, it was found that a greater percentage of our respondents were males $(58.8 \%)$ while lesser percentage were female $(41.2 \%)$ and that the age range was from 21 to 40. Even further, all our hypotheses were strongly supported with the statistical findings.

Our assumption about cost and time savings in Hypothesis 1 (The greater the use of HRIS, the higher the operational savings in terms of cost and time) is statistically supported, and that there is a relatively strong and positive relationship between HRIS use and cost and savings, which also means that organizations that divert concerted efforts towards HRIS adoption and use have a high likelihood of cutting down cost and saving time. Decision making contributions (Hypothesis 2) - The greater the use of HRIS, the better the contributions to strategic decision making) also have high tendencies of improving effectiveness of HR decision if HRIS use is widely implemented. It was found that HRIS use will improve quality decisions by not less than 67 percent. Similarly, our assumption that HRIS will go a long way to add value to organizational competitive advantage and enhance the development of employees is statistically supported. A few concerns from our open-ended questions also provided considerable responses. Many respondents appear to be concerned about the cost of implementing a thorough HRIS system in organizations. Even beyond implementing, there are genuine qualms as to whether the systems can be maintained efficiently and cost-effectively.

\section{Conclusion}

In all, 57 HR stakeholders were sampled from three different organizations. In spite of the major revelation that HRIS use contributes a great deal to enhance variables such as cost and time savings (CTS), decision making contributions (DMC), quality information effects (QIE) employee development commitment (EDC), it is also worth noting that there is much that needs to be considered by the organizations in terms of HRIS planning, implementation and sustenance.

\section{References}

Ball, K. (2001). The Use of Human Resource Information Systems: a Survey. Personnel Review, 30 (6): 667-693.

Bamberger, P., Meshoulam, H. (2000). Human Resource Strategy: Formulation, Implementation, and Impact. Beverly Hills, CA: Sage,

Beadles, N., Lowery, C. M., \& Johns, K. (2005). The Impact of Human Resource Information Systems: An Exploratory Study in the Public Sector. Communications of the IIMA 39, 5 (4).

Broderick, R., Boudreau, J. W. (1992). Human Resource Management, Information Technology and The Competitive Edge. Academy of Management Executive, 6 (2), 7-17.

Brown, D. (2002). eHR - Victim of Unrealistic Expectations. Canadian HR Reporter, 15 (16), 1 - 6.

Davenport, T. H. (1993). Process Innovation. Boston, MA: Harvard Business School Press.

Florkowski, G. W. (2006). The diffusion of human-resource information-technology innovations in U.S and non-U.S. firms. Personnel Review, 35 (6), 684-710.

Haines, Victor Y., Petit, A. (1997). Conditions for Successful Human Resource Information Systems. Human Resource Management, 36 (2), 261-275.

Gardner Sharyn, D., Lepak David, P., Bartol Kathryn, M. (2003). Virtual HR: The Impact of Information Technology on Human Resource Professional. Journal of Vocational Behavior, 63 (2), 159-179.

DeSanctis, G. (1986). Human Resource Information Systems - A Current Assessment. MIS Quarterly, 10 (1), $15-27$.

Gupta, A. (2000). Enterprise Resource Planning: the emerging organizational value Systems. Industrial Management and Data Systems, 100 (3), 114-118. 
Hendrickson, R. (2003). Human Resources Information Systems: Backbone Technology of Contemporary Human Resources. Journal of Labor Research, XXIV (3).

Kotler, J. (1996). Leading Change. Boston, MA: Harvard Business.

Kossek, E. E., Young, W., Gash, C. D., Nichol, V. (1994). Waiting For Innovation in The HR Department: Godot Implements a HRIS. Human Resource Management, 33 (1), 135-59.

Kovach, K. A., Cathcart, C. E. Jr. (1999). Human resource information systems (HRIS): providing business with rapid data access, information exchange and strategic advantage. Public Personnel Management, 275-81.

Kovach, K. A., Hughes, A. A., Fagan, P., Maggitti, P. G. (2002). Administrative and strategic advantages of HRIS. Employment Relations Today, 29 (2), 43-48.

Lawler, E. E., Mohrman, S. A. (2003). HR as a strategic partner: what does it take to make it happen. Human Resource Planning, 26 (3), 15-29.

Lederer, A. L. (1984). Planning and developing a human resource information system. The Personnel Administrator, 29 (8), 27-39.

Lengnick-Hall, Mark L., \& Moritz, S. (2003). The Impact of e-HR on the Human Resource Management Function. Journal of Labor Research, 24 (3), 365-379.

Martinsons, M. G. (1994). Benchmarking human resource information systems in Canada and Hong Kong. Information \& Management, 26, 305-316.

Ngai, E.W.T., Wat, F. K. T. (2006). Human resource information systems: a review and empirical analysis. Personnel Review, 35 (3), 297-314.

Mayfield, J., Mayfield, M., \& Lunce, S. (2003). Human Resource Information Systems: A Review and Model Development. Advances in Competitiveness Research, 11 (1), 139-151.

Overman, S. (1992). Reaching for the 21st Century. HR Magazine, 37, 61-63.

Sadri, J., Chatterjee, V. (2003). Building organizational character through HRIS. International Journal of Human Resources Development and Management, 3 (1), 84-98.

Tannenbaum, S. I. (1990). Human ResourceIinformation Systems: User Group Implications. Journal of Systems Management, 41 (1), 27-32.

Tansley, C., Newell, S., William, H., (2001), Effecting HRM-style practices through an integrated human resource information system An e-Greenfield site? Personnel Review, 30 (3), 351-370.

Targowski, A. S., \& Deshpanade, S. P. (2001). The Utility and Selection of an HRIS. Advances in Competitive Research, 9 (1) 42-56.

Teo, T., Soon, G. L., Fedric, A. N. (2001). Adoption and Impact Of Human Resource Information Systems (HRIS). Research in Practice in Human Resource Management, 9 (1), 101-117.

Ulrich, D. (2001). Human Resource Champions: From e-business to e-HR. HRIM Journal, 5, 90-97.

Walker, A. J. (2001). How the Web and Other Trends are Changing Human Resources. In Alfred J. Walker, Ed., Web-Based Human Resources. New York: McGraw-Hill, 2001.

Watson, W. (2002). e-HR: Getting Results Along the Journey - 2002 Survey Report. Watson Wyatt Worldwide.

Wright, P. M., McMahan, G. C. (1992). Theoretical perspectives for strategic human resource management. Journal of Management, 18, 295-321.

Wright, P., \& Snell, S. (1991). Toward an integrative view of strategic human resource management. Human Resource Management Review, 1 (4), 203-225.

Advised by Ivars Muzis, Riga Teacher Training and Educational Management Academy,

Latvia

Received: September 29, 2012

Accepted: November 22, 2012

\begin{tabular}{|ll}
\hline Ebenezer Ankrah & $\begin{array}{l}\text { Lecturer, Central University College, P. O. Box 2305, Tema, Ghana. } \\
\text { E-mail: ebankrah@yahoo.com }\end{array}$ \\
\hline \multirow{2}{*}{ Evans Sokro } & Lecturer, Central University College, Miotso, P. O. Box 2305 Tema, Ghana. \\
& $\begin{array}{l}\text { Phone: +233 } 246448519 . \\
\text { E-mail: evansok@yahoo.com }\end{array}$
\end{tabular}

